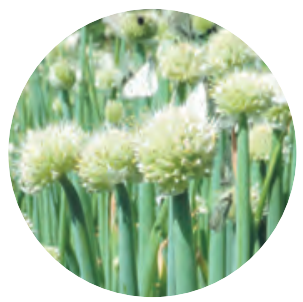

\title{
WELSH ONION (ALLIUM FISTULOSUM) VARIETY 'PREMYERA' FOR CONDITIONS OF THE SOUTH OF WESTERN SIBERIA
}

\author{
Шишкина Е.В. ${ }^{1}$ - С.Н.С \\ Жаркова С.В. ${ }^{2}$ - доктор с.-Х. наук, доцент, професссор каффедры \\ Малыхина О.В.' - Н.С. \\ 'Западно-Сибирская СООС - \\ филиал ФГБНУ «Федеральный научный центр овощеводства" \\ 656099, Россия, Алтайский край, г.Барнаул, Опытная станция, 22 \\ ФГБОУ ВО АлтайскИй ГАУ \\ 656049, Россия, Алтайский край, г.Барнаул, пр. Красноармейский, 98 \\ E-mail:stalina_zharkova@mail.ru
}

Использование многолетних луков в культуре, позволяет увеличить поступление зелёных листьев в ранневесенний период и снизить проблему недостатка витаминов. Наиболее востребованным из группы многолетних луков в промышленном и приусадебном овощеводстве по праву считается лук батун. Это достаточно неприхотливая культура, обладающая большими положительными качествами и свойствами. Сдерживающий фактор распространения этой культуры и наиболее интенсивного её внедрения в производство -отсутствие адагтированных к условиям выращивания сортов. Экспериментальная работа выполнена в 2008-2016 годах в лаборатории Западно-Сибирской стаНции ФГБНУ ФНЦО. Опыты для проведения исследовательской работы были заложены вне селекционного севооборота. Алтайскими учёными была проведена большая работа по сбору исходного материала лук батуна, дальнейшего его исследования и проведения отборов. B результате из образцов были отобраны клоны, обладающие хозяйственно ценными признаками. Образец №44 в 2016 году был передан в ГСИ, успешно его прошёл и внесен в Государственный реестр селекционных достижений как сорт Премьера. Сорт среднеспелый, период от массового отрастания листьев до начала хозяйственной годности составляет 20-28 суток. Одно из главных его практических достоинств - позднее стрелкование (4-14 июня), что позволяет продлить период хозяйственной годности посадок. По результатам испьпаний в среднем за три года новый сорт по товарной урожайности превосходит стандарт Нежность при одноразовой уборке в год посева на 32,2\% и при срезках в многолетней культуре - на 39,7\%

Ключевые слова: лук батун, образцы, отрастание, качество листьев, урожайность, клоновый отбор.

Для цитирования: Шишкина Е.В., Жаркова С.В., Малыхина О.В. СОРТ ЛУКА БАТУНА ПРЕМЬЕРА ДЛЯ УСЛОВИЙ ЮГА ЗАПАДНОЙ СИБИРИ Овощи России. 2019;(1):65-67. DOI:10.18619/2072-9146-2019-1-65-67
Shishkina Ye.V. ${ }^{1}$ - Senior Scientist

Zharkova S.V. ${ }^{2}$ - Dr. Agr. Sci., Assoc. Prof.

Malykhina O.V. ${ }^{1}$ - Scientist

West Siberian Vegetable experimental station - Branch of the Federal State Budgetary Scientific Institution "Federal Scientific Vegetable Center" 656099, Russia, Altai Region, Barnaul, Opytnaya stantsiya, 22 ${ }^{2}$ Altai State Agricultural University

656049, Russia, Altai Region, Barnaul, Krasnoarmeyskiy prospekt, 98 E-mail: stalina_zharkova@mail.ru

The cultivation of perennial onions may increase the availability of green leaves in the early spring period and reduce the problem of vitamin deficiency. Welsh onion (Allium fistulosum) is one of the most demanded crops of the perennial onion group both in commercial and household vegetable growing. This is quite low maintenance crop with a number of positive qualities and properties. The factor that constrains the spread of this crop and its most intensive introduction in commercial growing is the lack of varieties adapted to the growing conditions. The plant breeders of the Altai Region have made major efforts for collecting the source material of Welsh onion, studying it further and conducting the selection. As a result, the clones with economically valuable characters were selected from the candidate varieties. In 2016, the candidate variety No. 44 was submitted to the State Variety Testing, it went through the trials successfully, and was included in the State Register of Selection Achievements as Premyera variety. The variety is middle-ripening, the period from the mass regrowth of leaves to the beginning of economic life is 20-28 days. One of its main practical advantages is late formation of flower shoots (4-14 June), which makes it possible to extend the period of economic validity of landings. According to the results of tests, on average for three years, the new variety in marketable yield exceeds the standard Nezhnost with a onetime cleaning per year of sowing by $32.2 \%$ and with cuttings in perennial crops by $39.7 \%$.

Keywords: : welsh onion (Allium fistulosum), variety, regrowth, leaf quality, yielding capacity, clone selection.

For citation: Shishkina Ye.V., Zharkova S.V., Malykhina O.V. WELSH ONION (ALLIUM FISTULOSUM) VARIETY 'PREMYERA' FOR CONDITIONS OF THE SOUTH OF WESTERN SIBERIA. Vegetable crops of Russia. 2019;(1):65-67 (In Russ.) DOI:10.18619/2072-9146-2019-1-65-67
Одной из основных задач, которая созданной в начале XX века ЗападноСибирской овощной опытной станции, было получение новых сортов овощных культур, которые в сложных климатических условиях Сибири, низкой агротех- нической базы производства, показывали бы высокие урожаи. Работу по селекции вели по нескольким направлениям. По селекции, разработке агротехники новых сортов, ведению семеноводства луковых культур много лет работали здесь специалисты, преданные своему непростому и очень важному делу: Н.Г. Антипенко, Т.Ф.Даринская, О.А. Никонова, Г.П. Панина, Т.К. Слинько, Н.Т. Белоносова и др. В результате долгой, кропотливой работы были районированы и внесены в Государственный реестр селекционных достижений РФ, 
допущенных к использованию, сорта: лук репчатый - Соломенно желтый 3160/29, Однолетний сибирский, Ермак, Юконт, Велина, Золотое веретено; чеснок яровой - Алейский; чеснок озимый - Скиф, Осенний, Герман, Касмала, Томич, Сиреневый туман, Елизар; лук шалот - Сибирский желтый, Софокл, Серёжка, Сибирский янтарь, Жарптица, Яшма, Золото Алтая; лук шнитт Чемал; лук слизун - Грин, лук батун Премьера [1].

В последнее время возрос спрос на сорта многолетних луков. Многолетние луки растут в условиях Сибири повсеместно в природе. Многие ученые предполагают, что Сибирь является одним из районов - родоначальников многолетних луков []. Одним из основных востребованных и наиболее распространенных видов многолетних луков по праву считается лук батун. В Сибири культура лука батуна известна с давних времён. Такие учёные, как Харузин А.Н., Кюз П.П., Брызгалов В.И., Гринберг Е.Г., Водянова О.С и др. считают, что в диком виде лук батун встречается в Сибирском регионе, далее по степям Киргизии до озера Байкал и в Китае, и именно из этих мест культура получила своё распространение в европейскую часть России, Западную Европу и азиатские страны $[2,3,4,5]$. В настоящее время ареал распространения лука батуна фиксируется от Полярного круга до тропических стран. Возделывают не только отборы из дикорастущих форм, но и успешно ведётся селекционная работа, создаются и районируются сорта. В 2018 году в Государственный реестр селекционных достижений РФ, допущенных к использованию, внесено 52 сорта лука батуна [6]. Учитывая возможность многоцелевого использования культуры, этого количества явно недостаточно.

Целью исследований было изучение дикорастущих, местных форм культуры, сортов других научных учреждений и создание нового, адаптированного к условиям Алтайского края сорта лука батуна.

Материалы и методы исследований Экспериментальная работа выполнена в 2008-2016 годах в лаборатории Западно-Сибирской станции ФГБНУ ФНЦО. Опыты для проведения исследовательской работы были заложены вне селекционного севооборота. Работа была проведена согласно методических указаний: «Методика полевого опыта» Доспехова Б.А., «Методика государственного сортоиспытания с/х культур» (1975), «Методические указания по селекции луковых культур» (1997) $[7,8,9]$. Объектами исследований было 27 образцов лука батуна, полученных из различных научных учреждений, а также местные и селекционные формы.

В течение вегетации растений регистрировали наступление основных фенофаз: у растений первого года жизни отмечали единичные и массовые всходы (75\%), осеннее пожелтение листьев; у растений второго года -

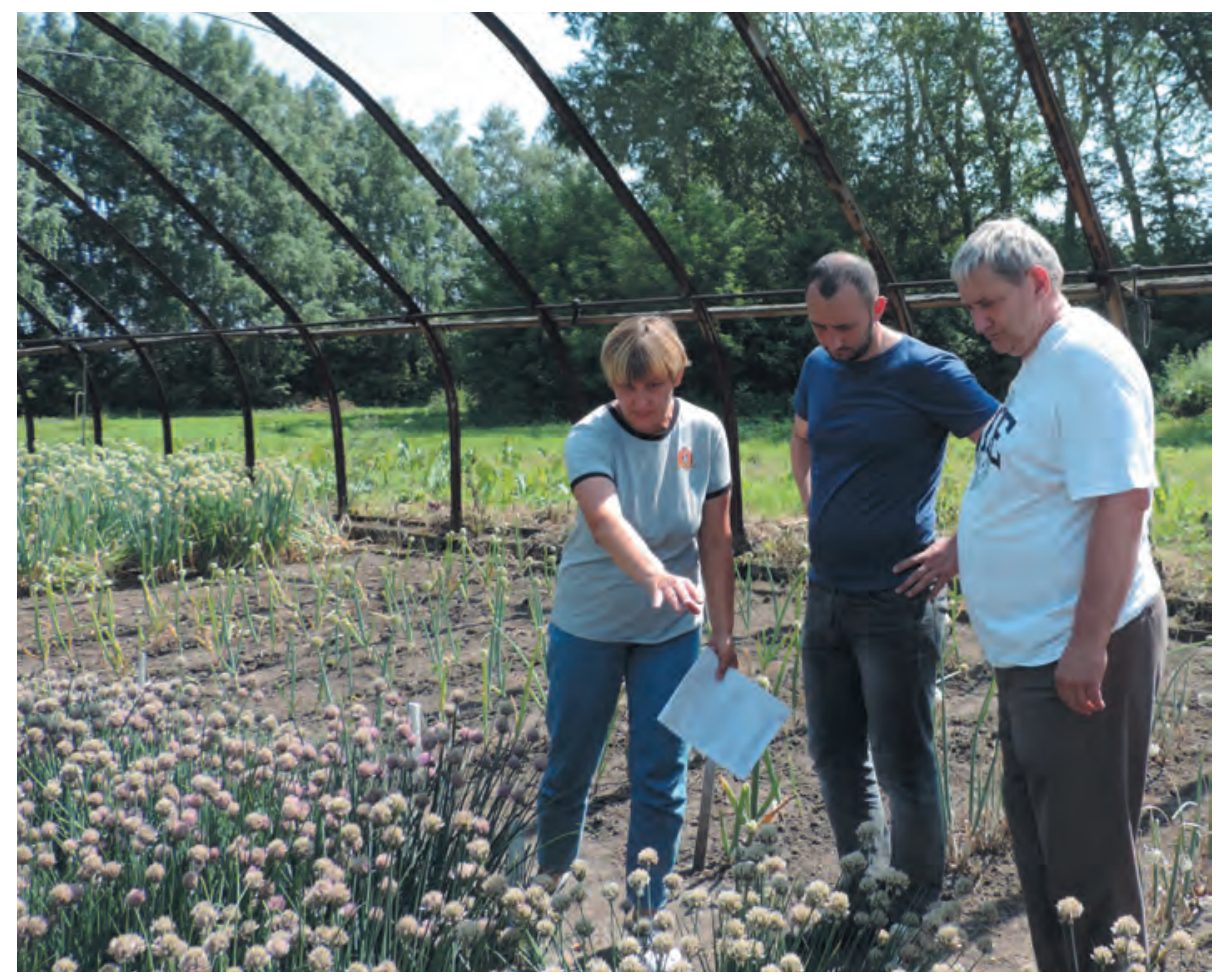

число перезимовавших растений, отрастание, время появления стрелок, растрескивание покрывала соцветия, начало и конец цветения, фазы зрелости семян (молочная, восковая, полная). При учете урожая весовым методом определяли массу товарной и нетоварной части урожая.

Морфологические наблюдения проводили по следующим показателям: число листьев на растении (шт.), длина растения (см), тип листа, форма поперечного среза листа, длина листа (см), ширина листа (см), окраска листа, степень воскового налета на листьях.

Биохимические исследования проведены в химической лаборатории станции с определением содержания сухого вещества по сухому остатку, общего сахара - по методу Бертрана, витамина C - по Мурри [10].

Статистическая обработка опытных данных проведена по общепринятым методикам и с помощью компьютерной программы Microsoft Office Excel.

\section{Результаты исследований}

В 2010 году по результатам проведённых исследований нами из исходного материала был отобран перспективный образец №44. Применяя в дальнейшей работе многократный массовый и клоновый отборы, образец был улучшен по хозяйственно ценным признакам, и в 2016 году был передан в Государственное сортоиспытание, который успешно прошёл и внесён в Государственный реестр как сорт Премьера (табл.).

Сорт Премьера среднеспелый, период от массового отрастания листьев до начала хозяйственной годности составляет 20-28 суток. Одно из главных его практических достоинств позднее стрелкование (4-14 июня), что позволяет продлить период хозяйственной годности посадок.

По результатам испытаний в среднем за три года новый сорт по товарной урожайности превосходит стандарт

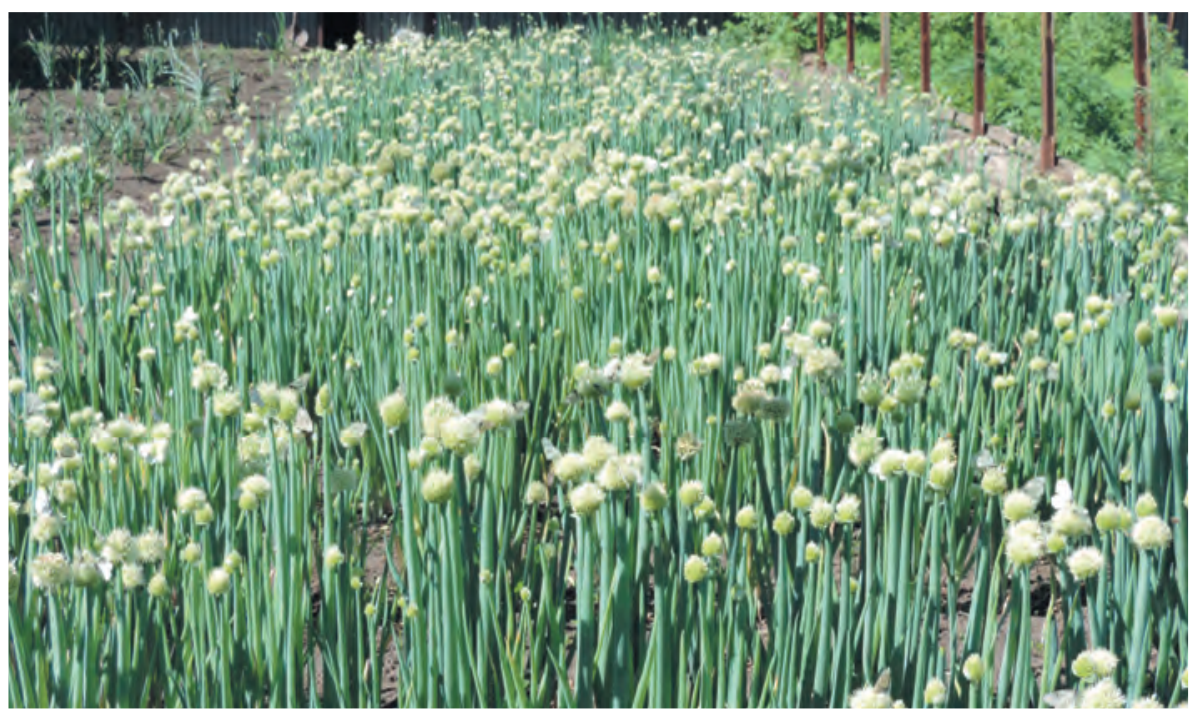

Питомник размножения. Сорт лука батуна Премьера. 
Таблица. Хозяйственно-биологическая характеристика

Table. Economic and biological characteristics

Показатели

Название

\begin{tabular}{|c|c|c|c|c|c|c|c|c|}
\hline \multirow{3}{*}{ Показатели } & \multicolumn{8}{|c|}{ Название } \\
\hline & \multicolumn{4}{|c|}{ Премьера - новый сорт } & \multicolumn{4}{|c|}{ Нежность - стандарт } \\
\hline & 2014 & 2015 & 2016 & среднее & 2014 & 2015 & 2016 & среднее \\
\hline $\begin{array}{l}\text { Период от полных всходов до уборки } \\
\text { (при однолетней культуре), суток }\end{array}$ & 45 & 45 & 45 & 45 & 45 & 45 & 45 & 45 \\
\hline $\begin{array}{l}\text { Период от начала отрастания до технической годности } \\
\text { (при многолетней культуре), суток }\end{array}$ & 28 & 20 & 20 & 22,7 & 30 & 22 & 22 & 24,6 \\
\hline $\begin{array}{l}\text { Общая урожайность, т/га при однолетней культуре } \\
\text { (уборка растений целиком) }\end{array}$ & 14,5 & 17,5 & 18,3 & 16,7 & 10,0 & 11,0 & 14,5 & 11,8 \\
\hline Товарная урожайность, т/га & 10,0 & 12,0 & 13,0 & 11,6 & 6,0 & 6,0 & 9,0 & 7,0 \\
\hline $\mathrm{HCP}_{05}$ & 2,2 & 1,9 & 1,7 & 1,9 & 2,2 & 1,9 & 1,7 & 1,9 \\
\hline Общая урожайность, т/га при многолетней культуре & 44,0 & 52,5 & 58,0 & 51,3 & 30,0 & 31,5 & 43,1 & 34,8 \\
\hline Товарная урожайность, т/га & 37,8 & 46,0 & 49,0 & 44,3 & 25,5 & 27,7 & 35,1 & 29,4 \\
\hline $\mathrm{HCP}_{05}$ & 2,8 & 3,1 & 2,9 & 2,9 & 2,8 & 3,1 & 2,9 & 2,9 \\
\hline Содержание сухого вещества, \% & 9,76 & 7,55 & 8,73 & 8,68 & 8,86 & 6,66 & 8,07 & 7,86 \\
\hline Содержание витамина С, мг\% & 74,35 & 60,95 & 61,97 & 65,73 & 56,55 & 50,13 & 50,35 & 52,3 \\
\hline Содержание сахаров, \% & 2,40 & 2,33 & 2,45 & 2,85 & 3,11 & 2,20 & 2,58 & 2,63 \\
\hline
\end{tabular}

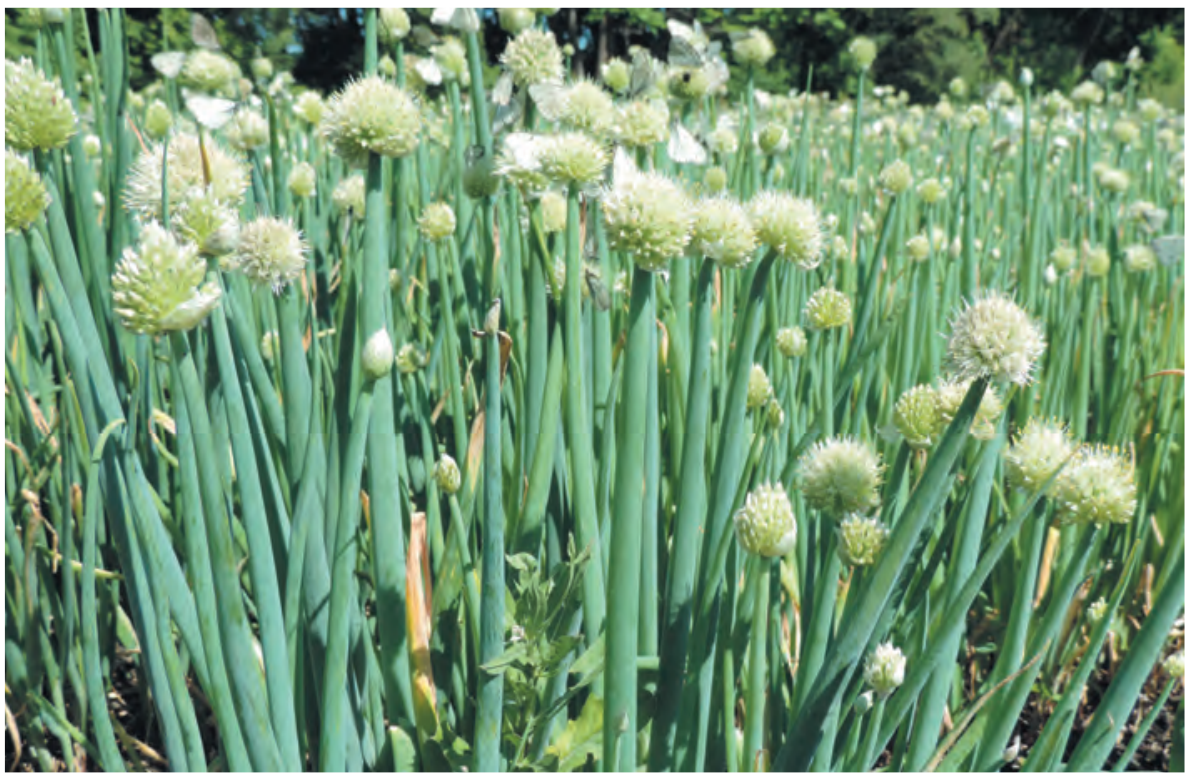

Цветущие растения лука батуна Сорт Премьера
Нежность при одноразовой уборке в год посева на 32,2\% и при срезках в многолетней культуре - на 39,7\%.

Показатели качества листьев (содержание витамина C, сухого вещества, общего сахара) у испытываемого образца также были значительно выше, чем у стандарта. Содержание витамина C (в среднем за три года) в листьях нового сорта выше, чем у стандарта на 20,5\%, сахаров - на 7,8\%, сухого вещества - на 10,2\%.

Сорт имеет прямостоячую мощную розетку листьев высотой до 58 см, высота ложного стебля - 10 см. Листья зеленые с средним восковым налетом. Длина листа - до 43 см, ширина - 1,9 см. Число листьев на один побег - 4,7 шт. Вкус листьев полуострый.

Расчет экономической эффективности в год сдачи сорта в ГСИ составил 490 тыс. руб/га за счет прибавки урожая.
- Литература

1. Жаркова С.В. Итоги селекционной работы по луковым культурам на юге Западной Сибири (лук репчатый, лук шалот, чеснок озимый)// Актуальные направления развития

научных исследований по картофелеводству и овощеводству: Сб.науч.тр. Междунар. Научно-практ.конференции к 80-летию Боброва Л.Г. Кайнар, 2008. C. $140-142$.

2. Харузин А.Н. Лук и чеснок / М.: «Новая деревня», 1928. - 141 с.

3. Кюз П.П. Овощеводство/ П.П.Кюз, В.А.Брызгалов// ОГИЗ «Сельхозиздат». М.-Л., 1934. $-710 \mathrm{c}$

4. Водянова О.С. Луки /Алматы, 2007. - 364 с.

5. Гринберг Е.Г. Луковые растения в Сибири и на Урале (батун, шнитт, слизун, ветвистый, алтайский, косой, многоярусный) / Е.Г.Гринберг, В.Г. Сузан// РАСХН. Сиб. Отделение ГНУ СибНИИРС. Новосибирск, 2007. - 224 с.

6. Государственный реестр селекционных достижений допущенных к использованию/Том 1. Сорта растений [Электронный ресурс]// Режим доступа: http://reestr.gossort.com/reestr (Дата обращения 01.08. 2018)

7. Доспехов Б.А. Методика полевого опыта опыта. - 5-изд. - М.: Агропромиздат, 1985. - $351 \mathrm{c}$.

8. Методика государственного сортоиспытания с.-х. культур. М., 1975. - С.87-121.

9. Методические указания по селекции луковых культур. М.: 1997. - 125 с.

10. Шифрина, Х.Б. Биохимия лука. В кн. Биохимия овощных культур / Л., М., 1961. c.328-400.
- References

1. Zharkova S.V. Results of selection work on onion crops in the south of Western Siberia (onion, shallot, winter garlic) // Actual directions of development Scientific Research on Potato and Vegetable Growing: Collected Scientific Papers. International Scientific and practical conference to the 80th anniversary of Bobrova L.G. Kaynar, 2008. P. 140-142.

2. Kharuzin A.N. Onions and garlic / M.: "New Village", 1928. 141 p.

3. Kuz P.P. Vegetable-growing / PPKyuz, V.A.Bryzgalov // OGIZ "Selkhozizdat". M. L., 1934. $710 \mathrm{p}$

4. Vodyanova O.S. Onions / Almaty, 2007. 364 p.

5. Grinberg E.G. Onion plants in Siberia and the Urals (batun, shnitt, slizun, branched, Altai, oblique, stacked) / E.G. Grinberg, V.G. Susan // RAAS. Sib. Branch of the GNU SibNIIRS. Novosibirsk, 2007. 224 p.

6. The state register of selection achievements approved for use / Volume 1. Plant varieties [Electronic resource] // Access mode: http://reestr.gossort.com/reestr (Contact date 01.08. 2018)

7. Dospekhov B.A. Methods of field experience experience. 5th ed. M.: Agropromizdat, $1985.351 \mathrm{p}$

8. Methods of state variety testing of crops. M., 1975. P.87-121.

9. Guidelines for the selection of onion crops. M: $1997.125 p$

10. Shifrina, H.B. Biochemistry of onions. In the book. Biochemistry of vegetable crops / L., M., 1961. P.328-400. 